\title{
Analysis of Three Phase Four Wire Inverter for UPS Fed Unbalanced Star Connected Load
}

\author{
${ }^{1} \mathrm{R}$. Senthil Kumar, ${ }^{2}$ Jovitha Jerome and ${ }^{1} \mathrm{~S}$. Nithya Bhama \\ ${ }^{1}$ Department of Electrical and Electronics Engineering, \\ Bannari Amman Institute of Technology, Anna University, Tamil Nadu, India \\ ${ }^{2}$ Department of Control and Instrumentation Engineering, \\ PSG College of Technology, Anna University, Tamil Nadu, India
}

\begin{abstract}
A Three phase inverter with a neutral connection i.e., three phase four wire inverter is proposed. The UPS system is fed by three phase four wire inverter and the load neutral point voltage is low to meet the requirement of the system. The four leg inverters effectively provide the neutral connection in three phase four wire system. They are used in many applications to handle the neutral current caused by the unbalanced and non-linear load. The unbalanced load becomes non-linear where the neutral of the loads are accessible. The four leg inverter produces the three output voltages independently with one additional leg. The main feature of a three phase inverter with an additional neutral leg is its ability to deal with load unbalance in a system. The goal of the three phase four leg inverter is to maintain the desired sinusoidal output voltage waveform for all loading conditions and transients. The neutral connection is present to handle the ground current due to unbalanced loads. The feasibility of the proposed modulation technique is verified by Matlab/Simulink.
\end{abstract}

Key words: Four wire inverter, rectifier, UPS, THD, switching network, India

\section{INTRODUCTION}

The primary function of an UPS is to maintain a constant voltage and constant frequency supply for critical loads, irrespective of variations in the input source or load condition ( $\mathrm{Li}$ and Smedley, 2009). The way of providing a neutral connection for three phase four wire systems using a four leg inverter topology by tying the neutral point to the mid point of the fourth neutral leg. The three phase four inverter has more control flexibility because two additional power switches doubles the number of inverter output states from $8\left(=2^{3}\right)-16\left(=2^{4}\right)$. This allows to improve the output waveform quality. In the medium or low power UPS; an output transformer is used to mitigate the neutral to earth voltage.

In the high power UPS, it is to eliminate the output transformer so that load is fed by the inverter directly, so the neutral of earth voltage is emerged. The currents flowing on each phase are generally not balanced so that a transformer is not required, a connection to the neutral terminal should be provided by adding an extra wire to the inverter. The load neutral terminal can be connected to the inverter using two topologies:
- Three phase four-wire in which the neutral point is connected directly to the midpoint of the supply by means of a capacitor divider

- Three phase four-leg, employing an additional inverter leg that permits to modify the neutral point voltage

The first topology is certainly simplest one but the three-phase inverter turns into three independent singlephase inverters. As consequence, zero-sequence harmonics are generated; moreover, especially when the load is unbalanced or non-linear, a high voltage ripple over supply capacitors is produced by neutral currents. A further limitation is represented by the maximum voltage value that the amplitude of each phase fundamental harmonic can reach.

The second topology requires additional power switches and a more complex control strategy but it offers different advantages such as an increased maximum output voltage value, a reduction of neutral currents and the possibility of neutral point voltage control (Bellini and Bifaretti, 2006a, b; Richard Zhang et al., 2002). The block diagram for the four wire inverter for online UPS as shown in Fig. 1. The main components of the UPS are rectifier, battery, four wire inverter, four wire inverter and load.

Corresponding Author: R. Senthil Kumar, Department of Electrical and Electronics Engineering, Bannari Amman Institute of Technology, Anna University, Tamil Nadu, India 
When the main supply is present, the rectifier provides power to an inverter as well as battery. The battery is charged. The inverter is on and feeds power to the load through UPS switch.

The UPS switch is always on and connects load to inverter output. When the UPS fails then load is connected directly to the mains directly through main switch. When the supply is not available then battery bank supplies power to an inverter.

Thus an inverter is always on and it takes power from rectifier or battery. The three phase four wire inverter is suitable for use in high power UPS for its advantage of feeding unbalanced load and the higher dc voltage utilization (Zeng et al., 2009).

As the load is fed by three phase three wire inverter is shown in Fig. 2. In this study, the load neutral point voltage for the three phase four leg inverter is proposed and it is shown in Fig. 3.

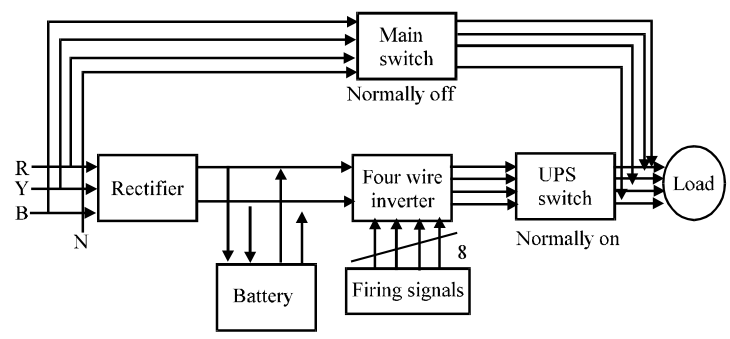

Fig. 1: Block diagram for four wire inverter

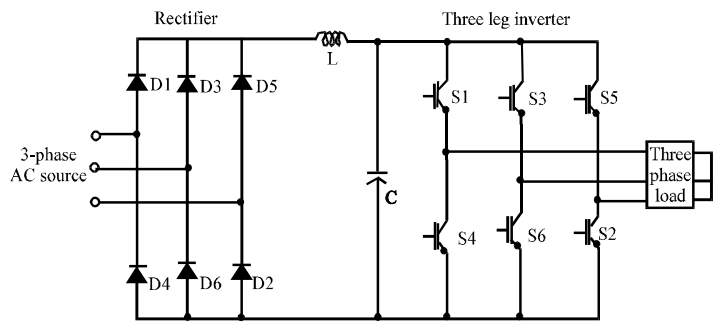

Fig. 2: Three phase three wire inverter

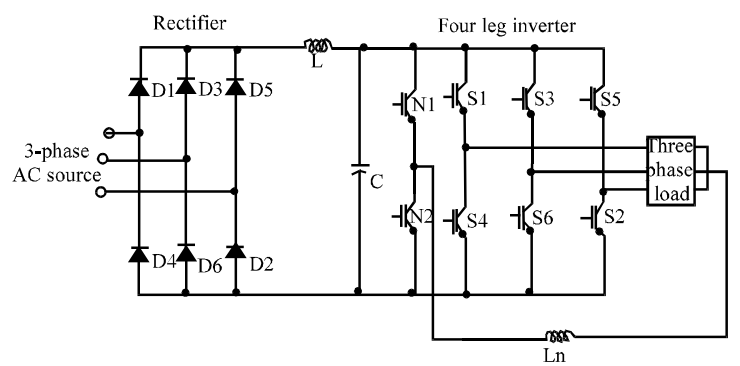

Fig. 3: Three phase four wire inverter

\section{MATERIALS AND METHODS}

Three phase four wire inverter: The three phase four wire inverter obtained by replacing the three wire switching network with a four wire switching network is shown in Fig. 4. The simplified diagram of four leg inverter circuit feeding four wire load is shown in Fig. 5. The neutral inductor $L_{n}$ can reduce switching frequency ripple. The switch in the inverter legs $R, Y, B, N$ denoted as $S_{k}\left(S_{R}, S_{Y}\right.$, $S_{B}$ and $S_{N}$ ) corresponds to each vector $V_{k}$ for $S=1$ upper switch in the inverter wire is conducting and for $S=0$ the lower switch is conducting.

The vector V (1011) represents switching state is shown in Fig. 5 (Ali and Kazmierkowski, 1998). The equivalent circuits for states (1011 and 1010) are represented in Fig. 6a, b, respectively.

The comparison of a three phase four wire voltage source inverter as shown in Table 1 . There are 16 switching states which are shown in Table 2; it can be taken from the graphical representation of switching vectors in Fig. 7. There are 14 non-zero voltage vectors and two zero vectors (1111 and 0000). The three phase variables $\mathrm{K}_{\mathrm{r}}, \mathrm{K}_{\mathrm{y}}$ and $\mathrm{K}_{\mathrm{b}}$ can be transferred as orthogonal coordinates $\mathrm{k} \alpha, \mathrm{k} \beta, \mathrm{k} \gamma$ using Eq. 1.

Any three phase sinusoidal set of quantities can be transformed to an orthogonal reference. For given switching states of the inverter, the voltage vector components can be calculated as:

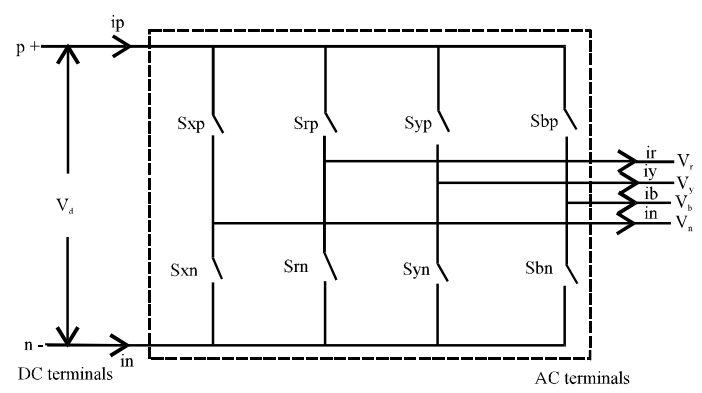

Fig. 4: Four wire switching network

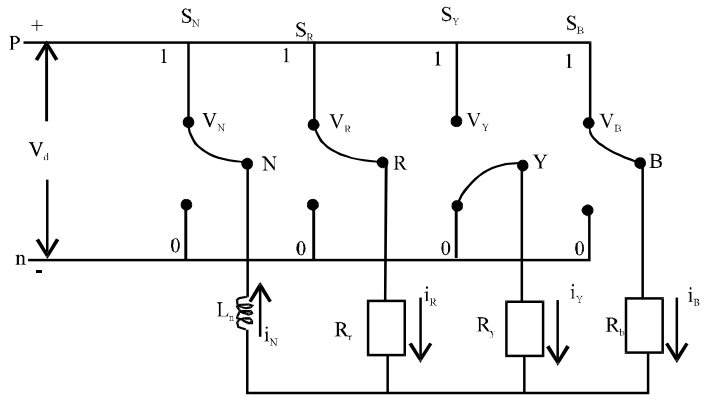

Fig. 5: Simplified diagram for four wire inverter 
Int. J. Elec. Power Eng., 4 (2): 38-44, 2010

Table 1: Comparison of four wire three phase inverter

\begin{tabular}{lll}
\hline Parameters & Three phase three wire load & Three phase four wire load \\
\hline $\begin{array}{l}\text { Number of required power switches } \\
\text { Equivalent topology }\end{array}$ & 6 & 8 \\
$\begin{array}{l}\text { Number of the output vectors } \\
\text { Maximum achievable peak value }\end{array}$ & Three independent single phase half bridge & Three dependent single phase full bridge \\
of line to neutral voltage & $0.5 \mathrm{Vd}$ & $16(14$ active +2 zero vectors \\
\hline
\end{tabular}

Table 2: Switching combination and output voltages for three phase four wire inverter

\begin{tabular}{llll}
\hline $\mathrm{S}_{\mathrm{R}}, \mathrm{S}_{\mathrm{Y}}, \mathrm{S}_{\mathrm{B}}, \mathrm{S}_{\mathrm{N}}$ & $\mathrm{V} \alpha$ & $\mathrm{V} \beta$ & $\mathrm{V} \gamma$ \\
\hline 0000 & 0 & 0 & 0 \\
0001 & 0 & 0 & $-\mathrm{V}_{\mathrm{d}}$ \\
0010 & $-1 / 3 \mathrm{~V}_{\mathrm{d}}$ & $-1 / \sqrt{3 \mathrm{~V}_{\mathrm{d}}}$ & $1 / 3 \mathrm{~V}_{\mathrm{d}}$ \\
0011 & $-1 / 3 \mathrm{~V}_{\mathrm{d}}$ & $-1 / \sqrt{3 \mathrm{~V}_{\mathrm{d}}}$ & $-2 / 3 \mathrm{~V}_{\mathrm{d}}$ \\
0100 & $-1 / 3 \mathrm{~V}_{\mathrm{d}}$ & $1 / \sqrt{3 \mathrm{~V}_{\mathrm{d}}}$ & $-1 / 3 \mathrm{~V}_{\mathrm{d}}$ \\
0101 & $-1 / 3 \mathrm{~V}_{\mathrm{d}}$ & $1 / \sqrt{3 \mathrm{~V}_{\mathrm{d}}}$ & $-2 / 3 \mathrm{~V}_{\mathrm{d}}$ \\
0110 & $-2 / 3 \mathrm{~V}_{\mathrm{d}}$ & 0 & $2 / 3 \mathrm{~V}_{\mathrm{d}}$ \\
0111 & $-2 / 3 \mathrm{~V}_{\mathrm{d}}$ & 0 & $-1 / 3 \mathrm{~V}_{\mathrm{d}}$ \\
1000 & $2 / 3 \mathrm{~V}_{\mathrm{d}}$ & 0 & $1 / 3 \mathrm{~V}_{\mathrm{d}}$ \\
1001 & $2 / 3 \mathrm{~V}_{\mathrm{d}}$ & 0 & $-2 / 3 \mathrm{~V}_{\mathrm{d}}$ \\
1010 & $1 / 3 \mathrm{~V}_{\mathrm{d}}$ & $-1 / \sqrt{3 \mathrm{~V}_{\mathrm{d}}}$ & $2 / 3 \mathrm{~V}_{\mathrm{d}}$ \\
1011 & $1 / 3 \mathrm{~V}_{\mathrm{d}}$ & $-1 / \sqrt{3 \mathrm{~V}_{\mathrm{d}}}$ & $-1 / 3 \mathrm{~V}_{\mathrm{d}}$ \\
1100 & $1 / 3 \mathrm{~V}_{\mathrm{d}}$ & $1 / \sqrt{3 \mathrm{~V}_{\mathrm{d}}}$ & $2 / 3 \mathrm{~V}_{\mathrm{d}}$ \\
1101 & $1 / 3 \mathrm{~V}_{\mathrm{d}}$ & $1 / \sqrt{3 \mathrm{~V}_{\mathrm{d}}}$ & $-1 / 3 \mathrm{~V}_{\mathrm{d}}$ \\
1110 & 0 & 0 & $\mathrm{~V}_{\mathrm{d}}$ \\
1111 & 0 & 0 & 0 \\
\hline
\end{tabular}

$$
\left(\begin{array}{l}
\mathrm{k} \alpha \\
\mathrm{k} \beta \\
\mathrm{k} \gamma
\end{array}\right)=2 / 3\left[\begin{array}{ccc}
\cos \theta & \cos (\theta-2 \pi / 3) & \cos (\theta-4 \pi / 3) \\
\sin \theta & \sin (\theta-2 \pi / 3) & \sin (\theta-4 \pi / 3) \\
1 / 2 & 1 / 2 & 1 / 2
\end{array}\right]\left[\begin{array}{l}
\mathrm{kr} \\
\mathrm{ky} \\
\mathrm{kb}
\end{array}\right](1)
$$

Where $\theta$ is the angle of orthogonal set $\alpha-\beta-0$ with respect to arbitrary reference. If $\alpha-\beta-0$ axes are stationary and the $\alpha$-axis is aligned with the- axis, then $\theta=0$ at all times. Thus, we get:

$$
\left(\begin{array}{l}
\mathrm{k} \alpha \\
\mathrm{k} \beta \\
\mathrm{k} \gamma
\end{array}\right)=2 / 3\left[\begin{array}{ccc}
1 & -1 / 2 & -1 / 2 \\
0 & \sqrt{3} / 2 & \sqrt{3} / 2 \\
1 / 2 & 1 / 2 & 1 / 2
\end{array}\right]\left[\begin{array}{l}
\mathrm{kr} \\
\mathrm{ky} \\
\mathrm{kb}
\end{array}\right]
$$

The above matrix can be rewritten as:

$$
\begin{gathered}
\mathrm{V} \alpha=1 / 3 \cdot \mathrm{V}_{d}\left(2 \mathrm{~S}_{\mathrm{R}}-\mathrm{S}_{\mathrm{Y}}-\mathrm{S}_{\mathrm{B}}\right) \\
\mathrm{V} \beta=1 / 3 \cdot \mathrm{V}_{\mathrm{d}}\left(\mathrm{S}_{\mathrm{Y}}-\mathrm{S}_{\mathrm{B}}\right) \\
\mathrm{V} \boldsymbol{\gamma}=-1 / 3 \cdot \mathrm{V}_{\mathrm{d}}\left(3 \mathrm{~S}_{\mathrm{N}}-\left(\mathrm{S}_{\mathrm{R}}+\mathrm{S}_{\mathrm{Y}}+\mathrm{S}_{\mathrm{B}}\right)\right)
\end{gathered}
$$

Circuit description of four wire voltage source inverter: The three phase four wire voltage source inverter, commonly used for three phase voltage generation is shown in Fig. 8.

It consists of eight switches $S_{\mathrm{rp}}-\mathrm{S}_{\mathrm{zn}}$ and filter of inductor $L_{R}-L_{X}$ and capacitors $C_{R}-C_{B}$. The $L C$ filter filters out the switching harmonics. The voltage source

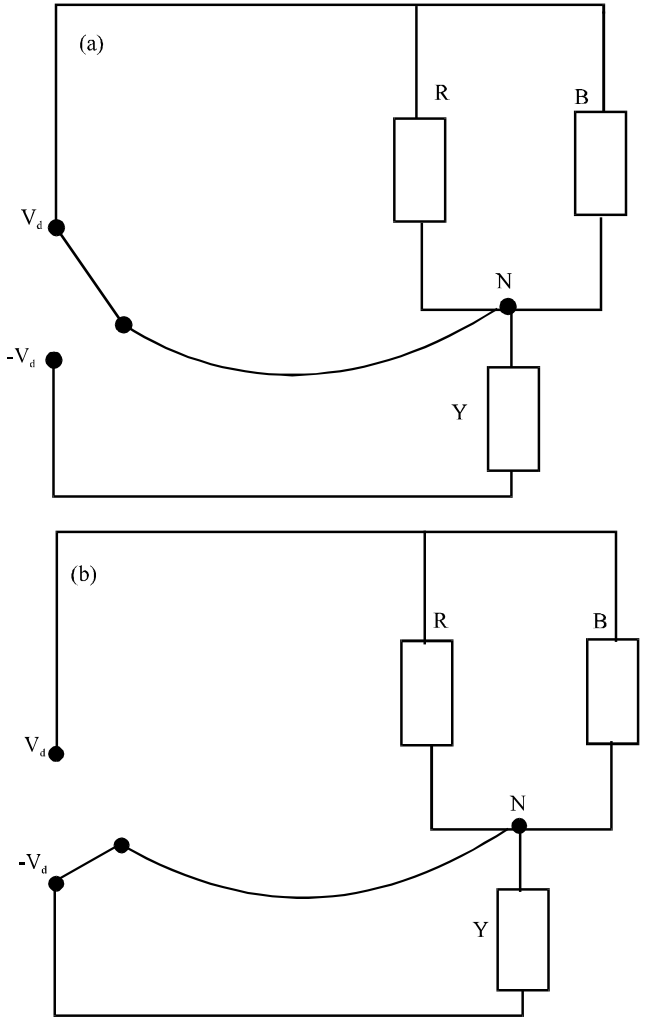

Fig. 6: (a) For switching state $\mathrm{S}_{\mathrm{R}}, \mathrm{S}_{\mathrm{Y}}, \mathrm{S}_{\mathrm{B}}, \mathrm{S}_{\mathrm{N}}, 1011, \mathrm{~V}_{\mathrm{RN}}=$ $\mathrm{V}_{\mathrm{BN}}=0$ and $\mathrm{V}_{\mathrm{YN}}=-2 \mathrm{~V}_{\mathrm{d}}$ (b) for switching state $\mathrm{S}_{\mathrm{R}}$, $\mathrm{S}_{\mathrm{Y}}, \mathrm{S}_{\mathrm{B}}, \mathrm{S}_{\mathrm{N}}, 1010 \mathrm{~V}_{\mathrm{RN}}=\mathrm{V}_{\mathrm{BN}}=2 \mathrm{~V}_{\mathrm{d}}$ and $\mathrm{V}_{\mathrm{YN}}=0$

inverter able to generate balanced and high quality $\mathrm{AC}$ output voltage shown in Fig. 8. In the three phase output voltage waveform shown in Fig. 8, one line cycle is divided into six regions.

In region $0^{\circ}-60^{\circ}, 120^{\circ}-180^{\circ}$ and $240^{\circ}-300^{\circ}$, the voltage waveforms in Fig. 8 have similar pattern i.e., one-phase voltage is always lower than the other two ( $\mathrm{Li}$ and Smedley, 2009). The modulation method for four wire inverter are:

- The switch $S_{\text {in }}(i=r, y, b)$ for the phase with the lowest voltage is always turned on and the corresponding $\mathrm{S}_{\mathrm{ip}}$ for this phase is always turned off

- The switches $S_{\text {in }}$ and $S_{\text {ip }}$ for the other two phases are driven complementarily 
- The switches $S_{x n}$ and $S_{x p}$ for the neutral phase are driven complementarily

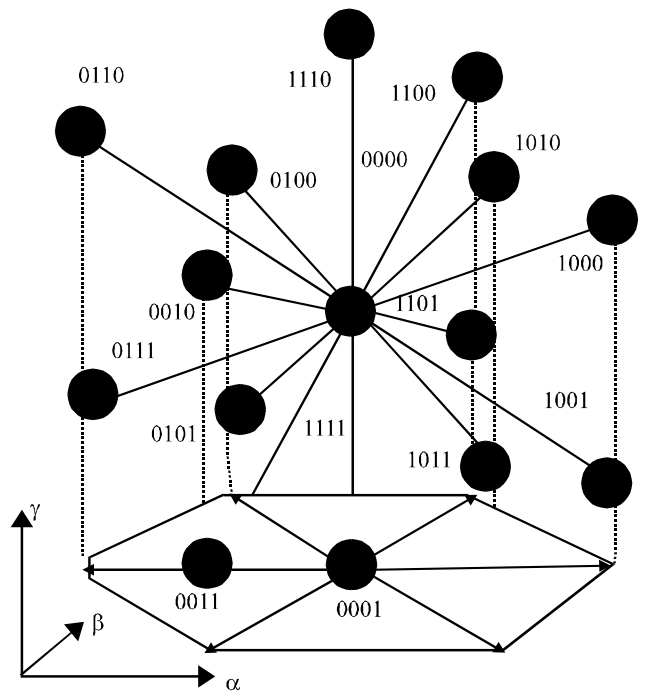

Fig. 7: Switching vectors for three phase four wire inverter

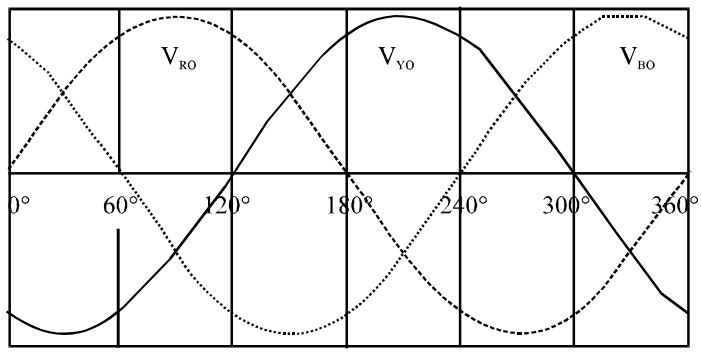

Fig. 8: Three phase output voltages

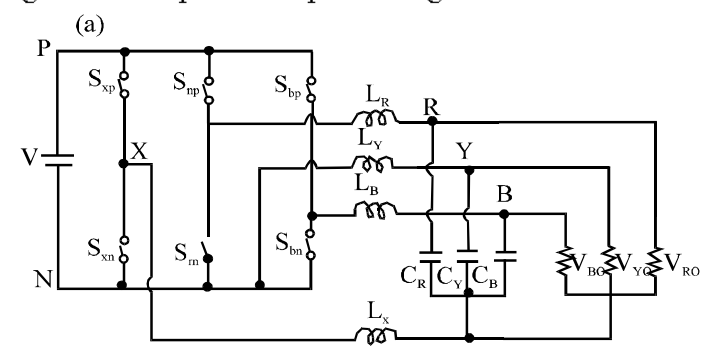

(b)

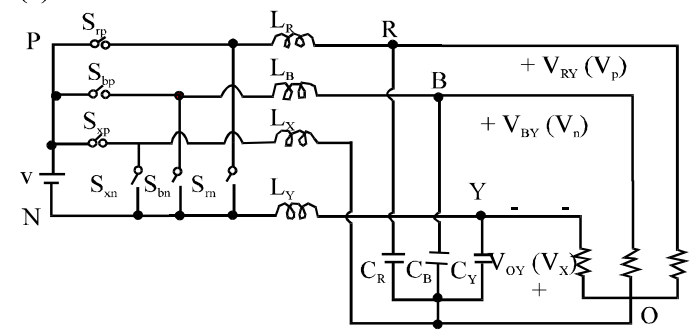

Fig. 9: Equivalent circuit for four wired VSI for $0^{\circ}-60^{\circ}$
The main circuit diagram in Fig. 3 is equivalent to Fig. 9a in $0^{\circ}-60^{\circ}$ region which can be further organized into Fig. 9b. The same equivalent circuit is also applicable to $120^{\circ}-180^{\circ}$ and $240^{\circ}-300^{\circ}$ regions.

The switching of the inverter is shown in Table 3 . In region $60^{\circ}-120^{\circ}, 180^{\circ}-240^{\circ}$ and $300^{\circ}-360^{\circ}$, the voltage waveforms in Fig. 8 have another pattern i.e., one phase voltage is always higher than the other two ( $\mathrm{Li}$ and Smedley, 2009). The modulation method for four wire inverter are:

- The switch $S_{i p}(i=r, y, b)$ for the phase with the highest voltage is always turned $\mathrm{ON}$ and the corresponding $\mathrm{S}_{\text {in }}$ for this phase is always turned off

- The switches $S_{\mathrm{ip}}$ and $\mathrm{S}_{\mathrm{in}}$ for the other two phases are driven complementarily

- The switches $\mathrm{S}_{\mathrm{xn}}$ and $\mathrm{S}_{\mathrm{xp}}$ for the neutral phase are driven complementarily

With this Fig. 3 is equivalent to Fig. $10 \mathrm{a}$ in $60^{\circ}-120^{\circ}$ region, which can be further organized into Fig. 10b. The same equivalent circuit is also applicable to $180^{\circ}-240^{\circ}$ and $300^{\circ}-360^{\circ}$ regions. The switching of the inverter is shown in Table 3. For further analysis, following assumptions are made:

- $\quad \mathrm{L}_{\mathrm{R}}=\mathrm{L}_{\mathrm{Y}}=\mathrm{L}_{\mathrm{B}}=\mathrm{L}_{\mathrm{X}}=\mathrm{L}$

- $\mathrm{C}_{\mathrm{R}}=\mathrm{C}_{\mathrm{Y}}=\mathrm{C}_{\mathrm{B}}=\mathrm{C}$

Table 3: Switching logics for proposed controller

\begin{tabular}{lllllllll}
\hline Switches & S1 & S2 & S3 & S4 & S5 & S6 & N1 & N2 \\
\hline $0^{\circ}-60^{\circ}$ & ON & OFF & OFF & OFF & OFF & ON & ON & OFF \\
$60^{\circ}-120^{\circ}$ & ON & ON & OFF & OFF & OFF & OFF & OFF & ON \\
$120^{\circ}-180^{\circ}$ & OFF & ON & ON & OFF & OFF & OFF & ON & OFF \\
$180^{\circ}-240^{\circ}$ & OFF & OFF & ON & ON & OFF & OFF & OFF & ON \\
$240^{\circ}-300^{\circ}$ & OFF & OFF & OFF & ON & ON & OFF & ON & OFF \\
$300^{\circ}-360^{\circ}$ & OFF & OFF & OFF & OFF & ON & ON & OFF & ON \\
\hline
\end{tabular}

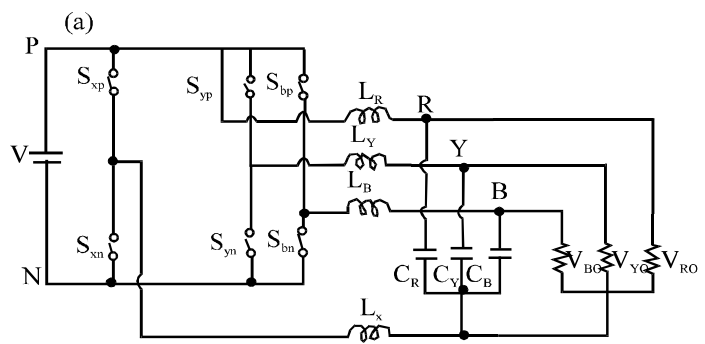

(b)

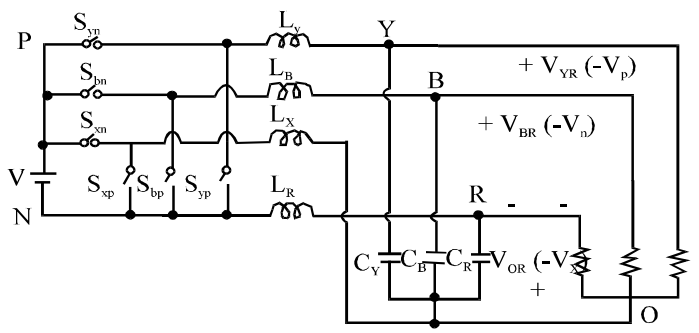

Fig. 10: Equivalent circuit for four wired VSI for $60^{\circ}-120^{\circ}$ 
- Switching frequency is much higher than fundamental frequency

\section{RESULTS AND DISCUSSION}

The Fig. 11 shows the three phase $\mathrm{AC}$ rectifier and its output. The earlier rectified output voltage in Fig. 12

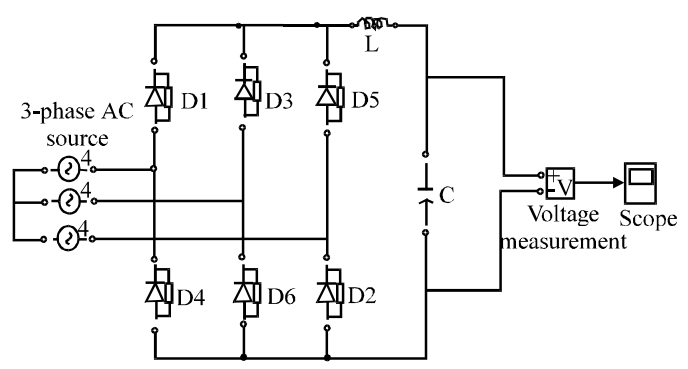

Fig. 11: Simulation circuit for rectifier

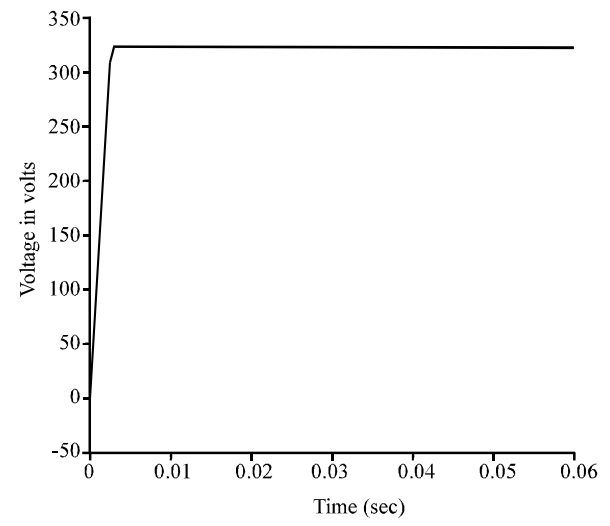

Fig. 12: Simulation result for rectifier obtained across the capacitor. The Fig. 13 is the three phase four wire inverter for online UPS is proposed. From the simulation analysis of Fig. 13:

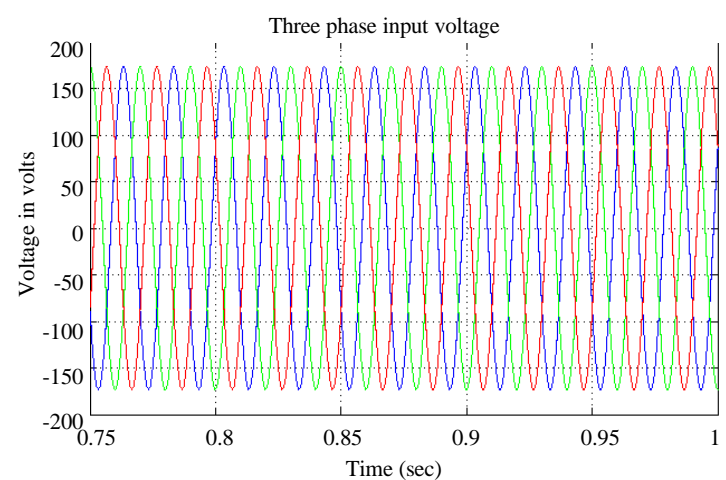

Fig. 14: Input voltage for three phase AC source

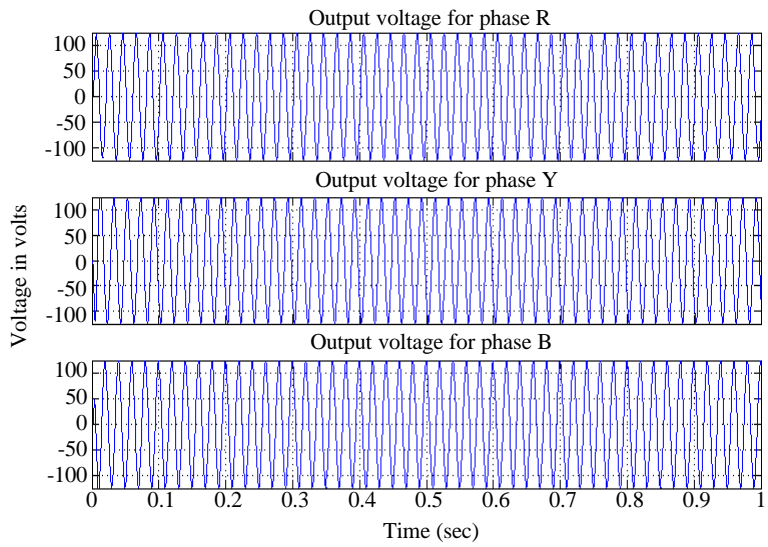

Fig. 15: Simulation result for four wire inverter

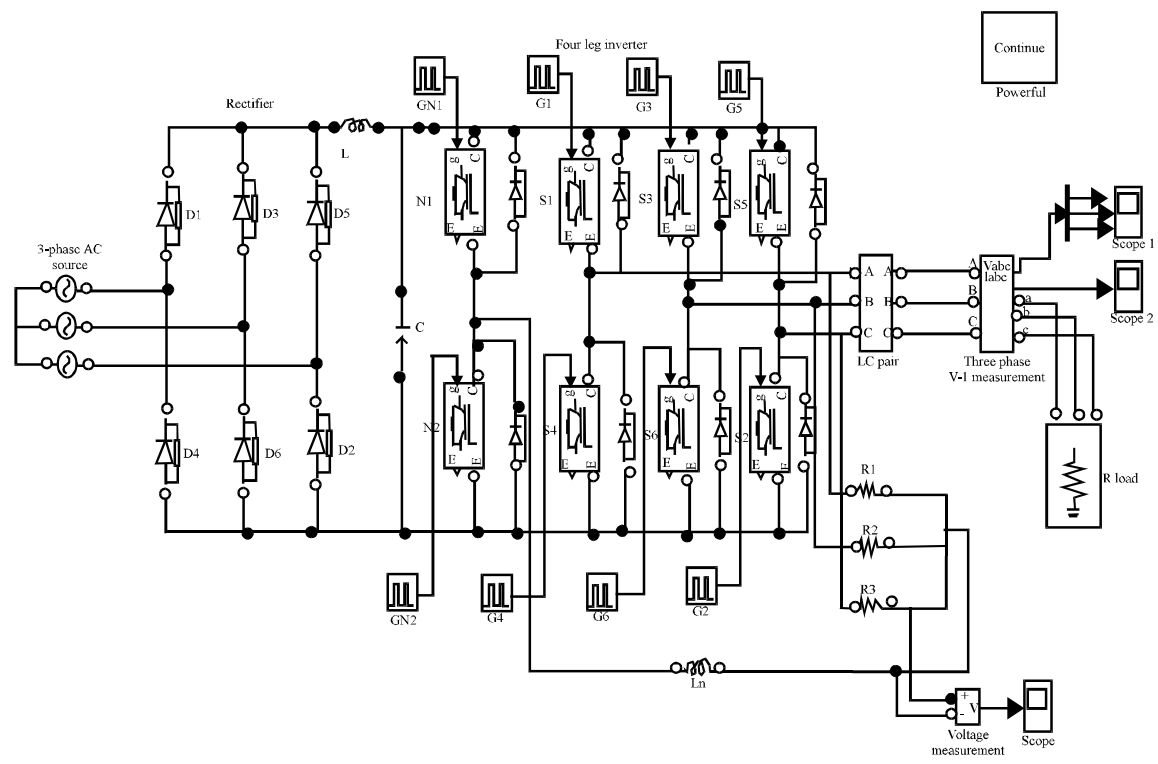

Fig. 13: Simulation circuit for three phase four wire inverter 
Int. J. Elec. Power Eng., 4 (2): 38-44, 2010

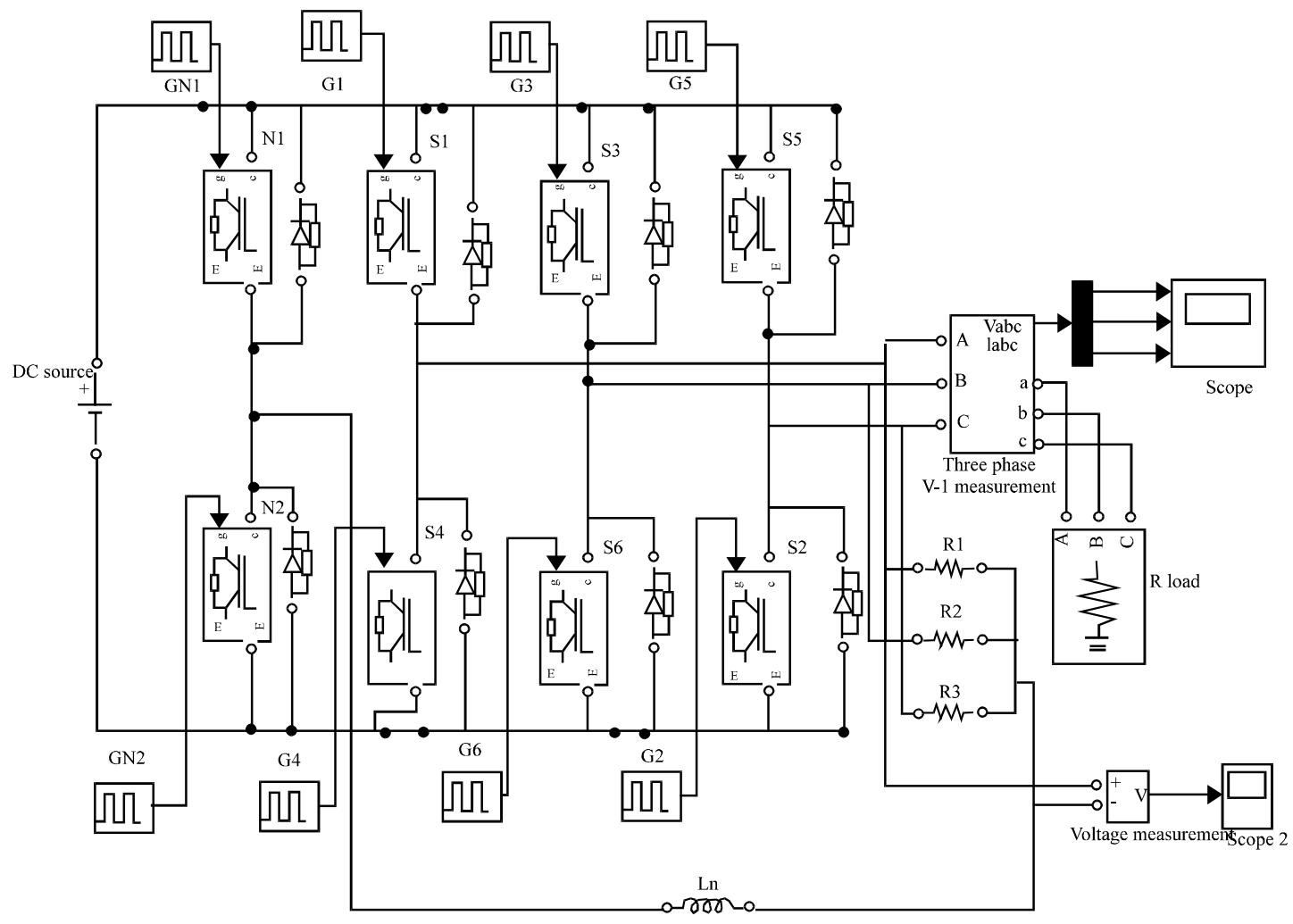

Fig. 16: Simulation circuit for DC source four wire inverter

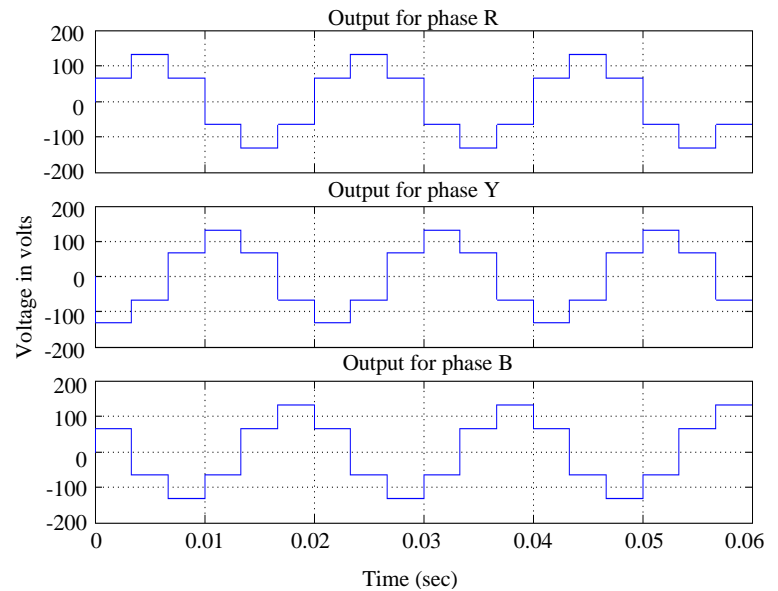

Fig. 17: Simulation result for three phase four wire inverter

- The wire $\mathrm{N}$ provides a lower impedance loop for unbalanced current and triplen harmonics, so the imbalance of output is dramatically reduced

- The neutral inductance $\mathrm{L}_{\mathrm{n}}$ can reduce the current that flows through the switching components of wire $\mathrm{N}$

The Fig. 14 is the three phase input source voltage for the UPS. The Fig. 15 is the simulation result for four

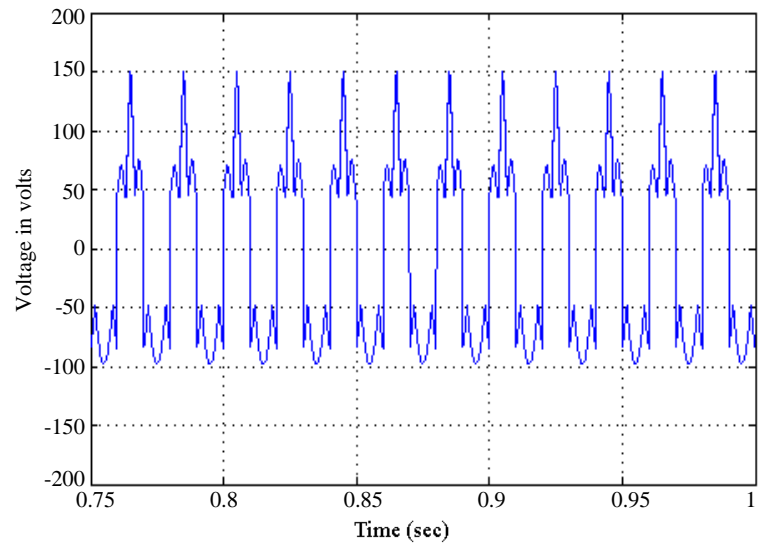

Fig.18: Simulation result for neutral voltage

wire inverter for three phase each output is phase shifted by $120^{\circ}$.

The Fig. 16 shows the DC source input voltage for four wire inverter.

Three line voltages $V_{R Y}, V_{Y B}$ and $V_{B R}$ are step waves, with step height $V_{\mathrm{dc}} / 2$ and $\mathrm{V}_{\mathrm{dc}}$. The three line voltages are mutually phase shifted by $120^{\circ}$ as shown in Fig. 17 . The neutral voltage wave form for four wire inverter as shown in Fig. 18. 
Table 4: Simulation result parameters

\begin{tabular}{ll}
\hline Parameters & Values \\
\hline Voltage for each phase & $100 \mathrm{~V}$ \\
Frequency & $50 \mathrm{~Hz}$ \\
DC input voltage & $200 \mathrm{~V}$ \\
Inductance (L) & $1 \mathrm{mH}$ \\
Capacitance (C) & $1000 \mu \mathrm{F}$ \\
Neutral inductance ( $\mathrm{Ln})$ & $1 \mathrm{mH}$ \\
Rated resistive load & $100 \Omega$ \\
\hline
\end{tabular}

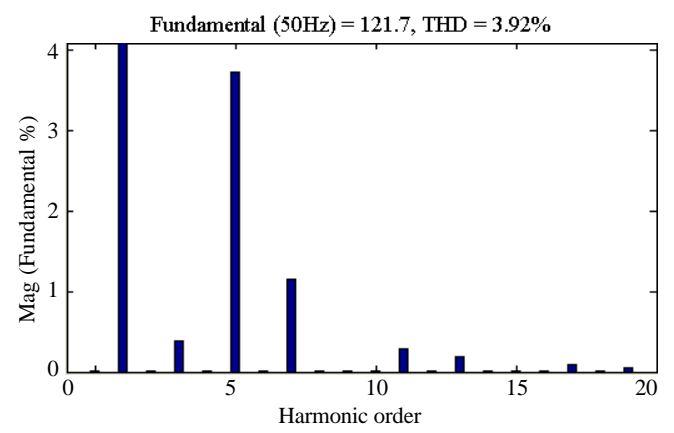

Fig. 19: THD level for three phase four wire inverter

Figure 19 shows the THD level for three phase four wire system. The harmonic distortion is reduced and its THD level is $3.92 \%$.

\section{CONCLUSION}

The three phase four wire UPS has been proposed in this study. The fourth wire makes the inverter have the ability of handling unbalancing loads. The inductor in fourth wire reduces the current through the switching components. The inverter control has the advantages of both lower switching to fundamental frequency ratio and outstanding ability to carry unbalanced loads.

\section{REFERENCES}

Ali, S.M. and M.P. Kazmierkowski, 1998. PWM voltage and current control of four-leg VSI. Proc. IEEE Int. Symp. Ind. Electr., 1: 196-201.

Bellini, A. and S. Bifaretti, 2006a. A simple control tecnique for three-phase four-leg inverters. International Symposium on Power Electronics, Electrical Drives, Automation and Motion, SPEEDAM206, May 2006.

Bellini, A. and S. Bifaretti, 2006b. Modulation techniques for three-phase four-leg inverters. Proceedings of the 6th WSEAS International Conference on Power Systems, Sept. 22-24, Lisbon, Portugal, pp: 389-403.

Li, L. and K.M. Smedley, 2009. A new analog controller for three-phase four-wire voltage generation inverters. IEEE Trans. Power Electron., 24: 1711-1721.

Zeng, L., L. Jinjun and L. Jin, 2009. Modeling, analysis and mitigation of load neutral point voltage for threephase four-leg inverter. Proceeding of the IEEE 6th International Power Electronics and Motion Control Conference.

Zhang, R., V.H. Prasad, D. Boroyevich and F.C. Lee, 2002. Three-dimentional space vector modulation IEEE Trans. Power Electron., 17: 31 4-326. 